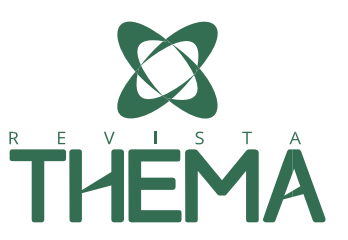

\section{Modelização didática como possibilidade de aprendizagem sobre divisão celular no ensino fundamental}

\section{Didactic modeling as a strategy for learning about cell division in elementary school}

Tiago Rodrigues da Silva ${ }^{1}$; Bruna Rodrigues da Silva²; Bruna Maria Prado da Silva ${ }^{3}$

\begin{abstract}
RESUMO
O objetivo do artigo foi analisar o desenvolvimento e aplicação de modelos didáticos para o ensino e a aprendizagem de divisão celular. Os modelos didáticos, de baixo custo e fácil obtenção, foram aplicados com 30 alunos no $8^{\circ}$ ano do ensino fundamental de uma escola pública de Timon, MA. Os dados foram coletados por meio da aplicação de um pré-teste, observações dos pesquisadores e pós-teste. $O$ pré-teste avaliou os conhecimentos após as aulas teóricas e o pós-teste como os conteúdos foram compreendidos pelos alunos com a utilização dos modelos didáticos. $\mathrm{O}$ uso dos modelos didáticos mostrou-se eficiente. $\mathrm{O}$ índice de acertos no pré-teste foi de $45 \%$ e após a intervenção metodológica passou a ser de $84 \%$. Os resultados mostram que os alunos desenvolveram habilidades para reconhecer e perceber as mudanças nas estruturas dos cromossomos durante as divisões celulares, compreendendo mitose e meiose de forma mais clara. Através dos modelos didáticos os estudantes tornaram-se construtores de seus conhecimentos. Conclui-se que, a modelização didática aplicada aos conteúdos conceituais de divisão celular permitiu uma melhor apresentação do modelo conceitual da mitose e meiose para os alunos.
\end{abstract}

Palavras-chave: Modelos didáticos; Células; Mitose; Meiose.

\begin{abstract}
The objective of this article was to analyze the development and application of didactic models as strategies for teaching and learning about the cell division process. The didactic models, with low cost and ease of obtaining, were applied with 30 students from the 8th grade of an elementary school in Timon, MA. The data were collected through the application of a pre-test, observations of the researchers, and a post-test. The pre-test evaluated the students' knowledge after the theoretical lectures, and the post-test determined how the students used the didactic models to understand the contents. The use of didactic models was efficient. The index hits in the pretest was $45 \%$, and after the methodological intervention, it was $84 \%$. The results showed that students have developed abilities to recognize and perceive the changes in the chromosome structures during cell divisions, understand mitosis and meiosis more clearly. Through the didactic models, the students became constructors of their own knowledge. Therefore, it was concluded that didactic modeling applied to the conceptual contents of cell division allowed a better teaching method of the conceptual model of mitosis and meiosis for elementary students.
\end{abstract}

Keywords: Didactic models; Cells; Mitosis; Meiosis.

\footnotetext{
${ }^{1}$ Rede municipal de Ensino de Timon, Timon/MA - Brasil.

2 IFPI - Instituto Federal de Educação, Ciência e de Tecnologia da Piauí, Teresina/PI - Brasil.

3 UFPI - Universidade Federal do Piauí, Teresina/PI - Brasil.
} 


\section{INTRODUÇÃO}

Os conteúdos que cercam a divisão celular são considerados de difícil abstração pelos alunos por causa de sua linguagem técnica e alta complexidade nos processos de mitose e meiose, como apontam os estudos de Braga (2010), Moul e Silva (2017), Pereira e Miranda (2017) e Tatsch e Sepel (2017). Cabe destacar, ainda, que as dificuldades de ensino e aprendizagem de mitose e meiose fazem parte de diversos conteúdos curriculares da educação básica, presentes na genética, biologia celular, fisiologia, etc.

Os estudantes possuem dificuldades em compreender os conceitos correlacionados de cromossomos, cromátides, DNA (ácido desoxirribonucleico) genes e, a distinção na formação das células somáticas (diploides) e gametas (haploides). Segundo Braga (2010), na aprendizagem há uma ênfase somente nos resultados da mitose e meiose ao originar duas células iguais e quatro diferentes, respectivamente. Na transposição didática de divisão celular, muitas vezes, ocorre uma ausência de compreender o comportamento dos cromossomos durante a mitose e meiose por parte dos alunos (MOUL; SILVA, 2017; TATSCH; SEPEL, 2017).

Sabe-se que a compreensão de mitose e meiose com suas abordagens quanto aos processos de divisão celular permitem aos alunos o entendimento da regeneração de tecidos, crescimento, funcionamento e diferenças genéticas entre os indivíduos. Além disso, esses conhecimentos são de fundamental importância para entender outros conteúdos ligados à biologia, em especial a genética.

No entanto, no cotidiano escolar os conteúdos de divisão celular são abordados de forma isolada, fragmentada e livresca, provocando uma aprendizagem que valoriza a memorização (BRAGA. 2010; MOUL; SILVA, 2017; PEREIRA; MIRANDA, 2017; TATSCH; SEPEL, 2017). Segundo Moreira (2012), essa aprendizagem apenas memorística é mecânica, servindo somente para as avaliações e exames.

Quanto às ilustrações dos processos de mitose e meiose presentes nos livros didáticos, Braga (2010) e Tatsch e Sepel (2017) afirmam que são em predominância com muitas informações e desvinculadas ao nível de ensino proposto, o que ocasiona em dificuldades em interpretá-las e na perda de interesse dos alunos pelos conteúdos. Além disso, os processos e componentes de divisão celular são a níveis microscópicos, o que requer para seu entendimento uma capacidade cognitiva para imaginar as estruturas que atuam na formação de novas células por mitose e meiose. Por isso, Tatsch e Sepel (2017) comentam que o ensino de divisão celular é fortemente ligado ao uso de imagens e esquemas.

O professor, nesse sentido, deve buscar metodologias alternativas de ensino através da produção de materiais pedagógicos, como por exemplo, os modelos didáticos que fornecem subsídios para superar abordagens que prevaleçam à passividade dos alunos durante a aprendizagem. O uso de modelos didáticos é importante para uma prática docente alternativa diante de conteúdos conceituais que, muitas vezes, são de difícil entendimento pelos estudantes, sobretudo aos assuntos ligados ao ensino de biologia (ORLANDO et al., 2009; SETÚVAL; BEJARANO, 2009; BRAGA, 2010; BARROS; OLIVEIRA, 2016; ALMEIDA, 2017; MOUL; SILVA, 2017).

Diante disso, se optou por desenvolver como proposta metodológica a construção de modelos didáticos, de baixo custo e fácil obtenção, para auxiliar nos processos de ensino e aprendizagem de mitose e meiose. Ademais, porque há a necessidade de superar as atividades de ensino tradicionais e livrescas, as quais ocorrem somente uma valorização da memorização dos alunos. Nesse sentido, o presente estudo trata-se de uma investigação que busca responder a seguinte problemática: Quais 
são as contribuições de modelos didáticos para o aprendizado dos conteúdos de divisão celular, aplicado no $8^{\circ}$ ano do ensino fundamental de uma escola pública em Timon, Maranhão?

O trabalho tem como objetivo analisar e verificar a utilização de modelos didáticos, simples, baratos e práticos, de mitose e meiose na aprendizagem dos alunos. Assim, discutir as contribuições da aplicação de modelos didáticos na promoção e construção de conhecimentos pelos estudantes.

\section{O USO DE MODELOS DIDÁTICOS NO ENSINO DE BIOLOGIA}

A modelização emergiu da necessidade de empregá-las para facilitar a aprendizagem dos alunos no ensino de ciências (KRAPAS et al., 1997; PAZ et al., 2006; ASTOLFI; DEVELAY, 2012; DUSSO et al., 2013). Dusso et al. (2013) aprofundam que os modelos pedagógicos são elaborados e aceitos como processos para uma aprendizagem no ensino de ciências/biologia e estão relacionados, principalmente, com as teorias da aprendizagem.

Krapas et al. (1997) inferem que os modelos podem ser conceituados como processos que representam determinados eventos, por meio de imagens e analogias, cuja finalidade é ajudar os alunos e cientistas na visualização e compreensão de algum conteúdo, e de modelagem como a construção dos modelos. Para os autores há três importantes modelos: (1) mentais que são construídos pelo indivíduo e expressam sua subjetividade em relação a algum fenômeno; (2) conceituais ou científicos que expressam o consenso da comunidade acadêmica sobre determinados fenômenos e (3) didáticos ou pedagógicos, elaborados e usados para facilitar no entendimento de um modelo científico.

A atividade de modelos e modelização no ensino de biologia, desse modo, indicam que a sua utilização tem por finalidade promover meios para os alunos compreenderem os modelos científicos. Para tanto, os modelos pedagógicos são fontes para desenvolver nos estudantes a capacidade de formular seus modelos mentais semelhantes aos conceituais (KRAPAS et al., 1997; PAZ et al., 2006; SETÚVAL; BEJARANO, 2009).

A utilização de modelos e modelagem no ensino de biologia ganha seu destaque como estratégia para promover uma transposição didática e facilitar a aprendizagem (PAZ et al., 2006; DUSSO et al., 2013; MOUL; SILVA, 2017). Com efeito, os professores de ciências/biologia passaram a fazer usos de maquetes e esquemas com o objetivo de solidificar suas explicações sobre os conteúdos para estabelecer maiores compreensões dos eventos naturais por parte dos estudantes (PAZ et al., 2006). Desse modo, Dusso et al. (2013) afirmam que os modelos didáticos usados no ensino de biologia são representacionais de um objeto, fenômeno ou evento.

A utilização de modelos pedagógicos nas aulas de biologia permitem a visualização dos processos microscópicos por meio de suas estruturas tridimensionais ou semi-planas e coloridas (ORLANDO et al., 2009). Além disso, são materiais viáveis na ausência de laboratórios de ciências equipados com os microscópios ou outros equipamentos que permitem observações das estruturas e fenômenos biológicos (ORLANDO et al., 2009; BARROS; OLIVEIRA, 2016). Os modelos didáticos também são instrumentos importantes na sala de aula, permitido uma manipulação, observação e análise dos conteúdos conceituais apresentados no livro didático (MOUL; SILVA, 2017). 


\section{METODOLOGIA}

A pesquisa foi desenvolvida por meio de abordagens qualitativas e descritivas quanto aos objetivos (LÜDKE; ANDRÉ, 2013). O estudo também pode ser caracterizado como uma pesquisa-ação, conforme Gil (2010), uma vez que se trata de estratégias participativas ao propor intervenções. Nesse caso, com a aplicação dos modelos didáticos.

Participaram do estudo uma turma de 30 alunos no $8^{\circ}$ ano do Ensino Fundamental de uma escola pública, a Unidade Escolar Luiz Miguel Budaruiche, localizada na zona urbana do município de Timon, MA. A escola situa-se no bairro Vila Angélica, região residencial de classe média baixa. A ausência de um laboratório de Ciências para desenvolvimento de atividades experimentais foi um dos principais motivos para escolha dessa unidade escolar. Além disso, esse estabelecimento de ensino consiste no local de atuação profissional de um dos autores, havendo, portanto, uma maior facilidade de acesso à escola, e abordagem do material didático com os alunos durante as aulas.

A intervenção metodológica foi realizada em três momentos pedagógicos, entre os meses de março e abril de 2018. Na primeira e terceira fases foram aplicados os pré-teste e pós-teste composto por 06 questões, quatro primeiras de múltipla escolha e duas discursivas, que abordavam os conteúdos conceituais acerca da divisão celular. Os testes continham as seguintes questões: (1) conceitos de cromossomos e cromátides; (2) relações entre cromossomos e DNA (ácido desoxirribonucleico); (3) células haploides; (4) células diploides; (5) conceitos e representação da mitose e (6) conceitos e representação da meiose. O objetivo do pré-teste foi averiguar a aquisição dos conceitos sobre divisão celular após as aulas teóricas e expositivas na sala de aula.

Assim, sua aplicação ocorreu ao término da apresentação dos conteúdos conceituais através de textos bases presentes no livro didático e estudos dirigidos. O pós-teste foi aplicado nos alunos ao término da utilização dos modelos didáticos desenvolvidos com o objetivo de averiguar o conhecimento dos alunos ao final da intervenção metodológica. O período entre a aplicação do pré-teste, dos modelos didáticos e pós-teste foram de 14 dias.

No segundo momento pedagógico houve a utilização dos modelos didáticos propostos com os alunos. A produção dos modelos surgiu a partir das observações durante as aulas expositivas, as quais os estudantes apresentaram dificuldades em compreender e visualizar os conceitos e as divisões sucessivas que caracterizam as divisões celulares. Os modelos didáticos desenvolvidos para o ensino e aprendizagem da divisão celular são compostos por um conjunto de células, cromossomos e cromátides com 10 e $8 \mathrm{~cm}$ de altura, respectivamente, e foram confeccionadas com folhas de E.V.A. (etil vinil acetato). Os modelos foram desenvolvidos com base nos referencias didáticos para nível fundamental proposto pelos autores Lederman e D'Olival (2015).

O modelo didático da mitose é constituído por 05 células que juntas formam o esquema simplificado que representa essa divisão celular. Isto é, cada célula representa as divisões sucessivas da mitose, desde a célula-mãe diploide (2n) com seu par de cromossomos homólogos, à duplicação do DNA, a divisão citoplasmática com a separação das cromátides e a formação das duas células-filhas diploides (Figura 1). 
Figura 1 - Modelos didáticos dos processos de divisão celular da mitose

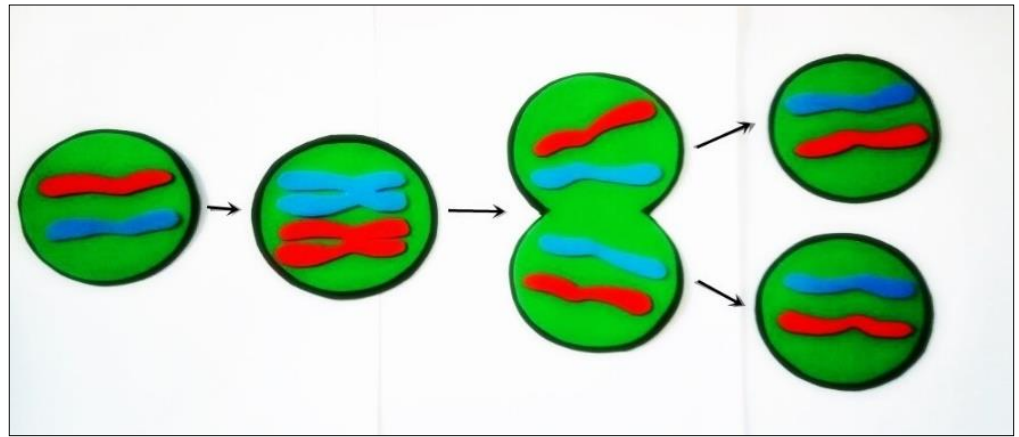

Fonte: Os autores, 2018.

De modo igual, o conjunto de 08 células forma o esquema representacional da meiose. Nesse modelo, ocorre também uma representação do par de cromossomos na célula parental, o par de cromossomos duplicados com as cromátides-irmãs, a separação dos cromossomos homólogos e cromátides, respectivamente. Sendo assim, também representa as divisões sucessivas que originam as quatro células-filhas haploides ( $\mathrm{n}$ ) (Figura 2).

Figura 2 - Modelos didáticos dos processos de divisão celular da meiose

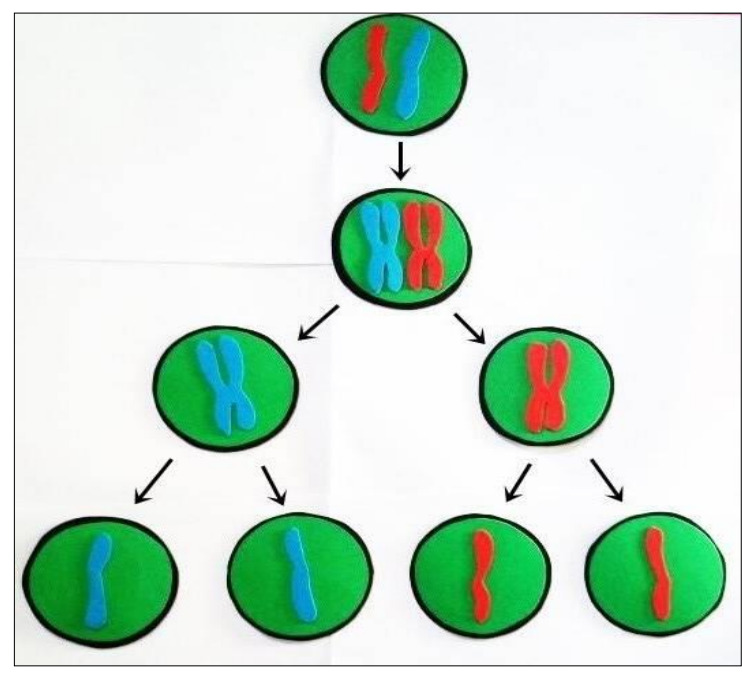

Fonte: Os autores, 2018.

Quanto a sua aplicação em sala de aula, os alunos foram organizados em grupos (com cinco integrantes) sendo utilizados 06 conjuntos de modelos de mitose e meiose e, ocorreu em três etapas.

1. Explicação expositiva e dialogada dos modelos pelo professor (fixados no quadro branco com fita adesiva), realizando demonstrações e discussões de cada etapa das divisões celulares e tirando as eventuais dúvidas dos alunos.

2. Manuseio dos modelos pelos alunos de forma aleatória e independente, a qual deveriam identificar as estruturas de cromossomos e cromátides, as células diploides e haploides, bem como executando montagens das divisões sucessivas que definem mitose e meiose (Figura 3).

3. Realização de um jogo de perguntas pelo professor aos grupos de alunos. O professor visitava cada grupo e lançava uma pergunta referente aos conteúdos abordados nos modelos e elegia um aluno para proferir a resposta, podendo haver a intervenção dos demais integrantes do grupo. 
Figura 3: Aplicação dos modelos didáticos

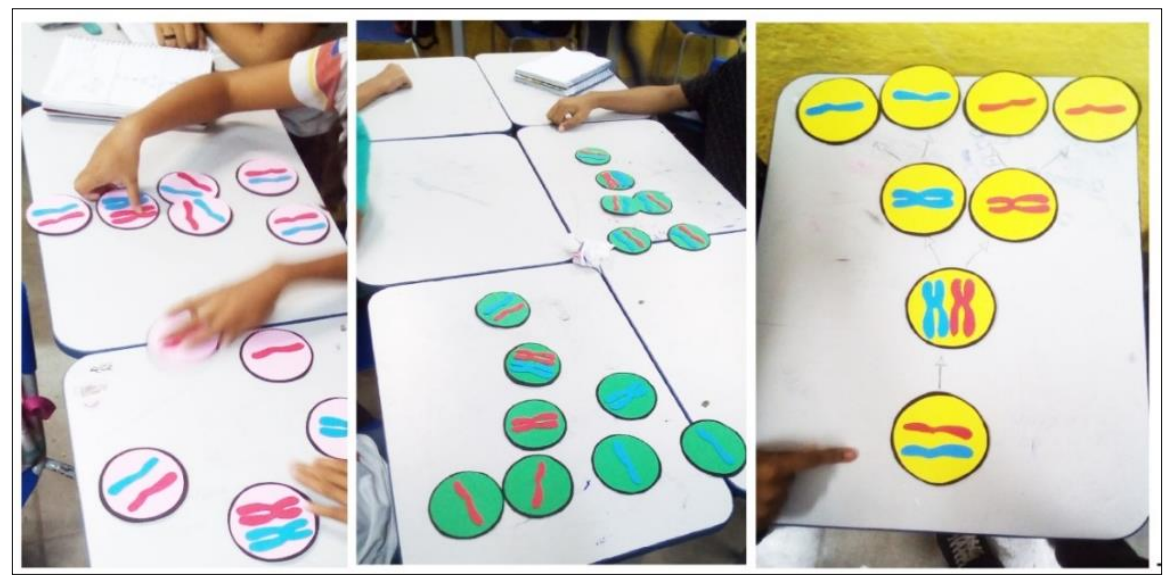

Fonte: Os autores, 2018.

O desempenho dos discentes em ambos os testes foram comparados e serviram de parâmetros para analisar os resultados da proposta metodológica na aprendizagem dos estudantes sobre mitose e meiose. As respostas dos alunos, individualmente, foram comparadas e categorizadas para análises qualitativas em certas e erradas considerando o proposto por Bardin (2011). As observações em sala de aula pelos pesquisadores durante as etapas da aplicação dos modelos didáticos também serviram na coleta de dados.

\section{RESULTADOS E DISCUSSÕES}

De início, foi perceptível a atenção e entusiasmo por parte dos alunos para manusear os modelos didáticos com a finalidade de identificar as estruturas e processos representados nos materiais produzidos. Contudo, no decorrer da aplicação dos modelos didáticos, se verificou dificuldades iniciais para as elaborações dos esquemas da mitose e meiose.

As principais dificuldades encontradas pelos alunos foram na identificação e compreensão dos modelos didáticos que trazem as mudanças estruturais que os cromossomos sofrem durante os processos de divisões celulares. A princípio, os estudantes focalizavam somente os resultados da mitose, duas células-filhas iguais, e meiose, quatro células-filhas diferentes. Não havia, de modo geral, uma atenção dos alunos em compreender os processos, as etapas que levam a formação de novas células nas divisões celulares.

Com o decorrer do manuseio dos modelos didáticos pelos alunos, notou-se entre os estudantes discussões sobre os processos celulares da mitose e meiose, bem como o desenvolvimento de uma autonomia para manusear os modelos didáticos. As questões que os alunos colocaram em suas conversas permitiram o professor identificar alguns conhecimentos assimilados pelos alunos durante as aulas expositivas. Na socialização dos conhecimentos entre os estudantes foi notado também que os argumentados não se limitaram em definir, identificar e quais são os resultados da mitose e meiose, de acordo com os modelos didáticos, mas sobre como ocorrem as suas respectivas divisões celulares.

A interação social proporcionada pelos modelos didáticos é um indicador da teoria de Vygotsky. Tendo em vista a troca de informações entre os alunos e desenvolvimento do trabalho em grupo e cooperação. Verifica-se, uma aprendizagem segundo a Zona de Desenvolvimento Proximal (ZDP). 
Segundo Davis e Oliveira (2010), a ZDP traduz o que um sujeito pode realizar sozinho e o que ele pode fazer com auxílio de um indivíduo com mais conhecimento.

Setúval e Bejarano (2009) quando abordam sobre modelos didáticos e aprendizagem, argumentam que os mesmos provocam um dinamismo na sala de aula, promovendo uma fixação de conteúdos ao articular teoria e prática. Sob esta óptica, o aluno desenvolve autonomia para manusear o material produzido ao observar e refletir sobre os processos representados no modelo didático. Por isso, na medida em que estão sendo aplicados ocorre o aumento da capacidade dos alunos em assimilar e raciocinar sobre o evento biológico (ORLANDO et al., 2009).

Com os modelos didáticos foram observados nos alunos mudanças conceituais sobre mitose e meiose, tais como células diploides, haploides, cromossomos e cromátide e, uma autonomia dos estudantes em identificar os conceitos que cercam os processos de divisão celular. Com isso, conclui-se na perspectiva sócio-histórica, que as independências dos estudantes correspondem para uma aprendizagem através da Zona de Desenvolvimento Real (ZDR). Trata-se do nível de aprendizado e desenvolvimento em que o indivíduo já é capaz de realizar atividades de forma independente (DAVIS; OLIVEIRA, 2010).

De fato, isso é percebido nos resultados dos pré-teste e pós-teste, pois houve uma melhoria na compreensão dos assuntos abordados após o uso dos modelos didáticos. Como se pode observar na Figura 4, dentre as 180 respostas avaliadas (30 alunos responderam 06 perguntas), resultaram em 81 acertos (45\%) no pré-teste e, $152(84 \%)$ acertos no pós-teste.

Figura 4: Percentuais de acertos e erros dos testes

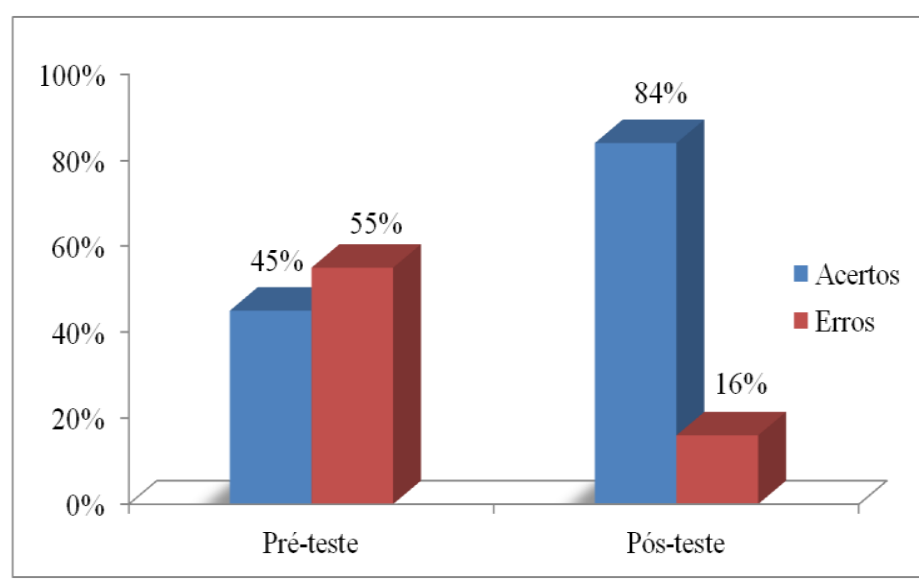

Fonte: Os autores, 2018.

De acordo com os resultados dos testes, o uso dos simples materiais didáticos propostos foi uma metodologia alternativa para o ensino de divisão celular e, portanto, eficaz para ampliar a capacidade de aprendizagem dos alunos dos conceitos básicos que requerem certo grau de imaginação e abstração. Assim, a aplicação de representações didáticas promove o surgimento da imagem e do imaginário dos processos biológicos ao estabelecer abordagens com os conteúdos conceituais através de analogias (ORLANDO et al., 2009; SETÚVAL; BEJARANO, 2009).

Torna-se possível dizer que a utilização dos modelos didáticos provocaram (re) construções dos conceitos discutidos nas aulas expositivas. Nestes termos, o uso dos modelos didáticos propostos se caracteriza como um instrumento que permitiu uma representação simples de uma ideia ou evento 
biológico como objeto de estudo cuja finalidade é facilitar a compreensão significativa dos alunos sobre esses processos (DUSSO et al., 2013).

Resultados semelhantes são encontrados nos estudos de Braga (2010), Almeida (2017), Moul e Silva (2017) que também verificaram as contribuições do uso de modelos didáticos para uma aprendizagem de mitose e meiose. Contudo, vale ressaltar que, esses estudos estão inseridos nas dificuldades do aprendizado de divisão celular no ensino médio, resultado direto de um ensino enciclopédico de biologia celular durante o ensino fundamental.

Por isso, o diferencial dos modelos didáticos aqui propostos não está somente no nível de ensino em que foi planejado e executado, mas também por promover uma abordagem conjunta durante o ensino e aprendizagem de mitose e meiose. Permite elucidar também a importância do desenvolvimento e aplicação de recursos didáticos alternativos desde o ensino fundamental.

Os dados obtidos com os testes nos levam a afirmar que a utilização de modelos didáticos sobre divisão celular promoveu o engajamento dos alunos para participar das atividades de forma reflexiva sobre o material produzido, o que aumenta as possibilidades de uma aprendizagem não mecânica. Outro ponto positivo, é que o professor se configura apenas como um mediador no processo de construção de conhecimentos pelos estudantes.

A diferença entre os acertos das respostas no pré-teste e pós-teste deixam evidenciado que a compreensão e aprendizagem sobre mitose e meiose por meio dos modelos didáticos propostos foram eficazes para melhorar o entendimento dos alunos. Com isso, para analisar de forma mais detalhada os resultados dos testes aplicados, a Figura 5 mostra uma análise comparativa dos acertos e erros por questão do pré-teste e pós-teste.

Figura 5: Comparação dos percentuais de respostas corretas por questão dos testes

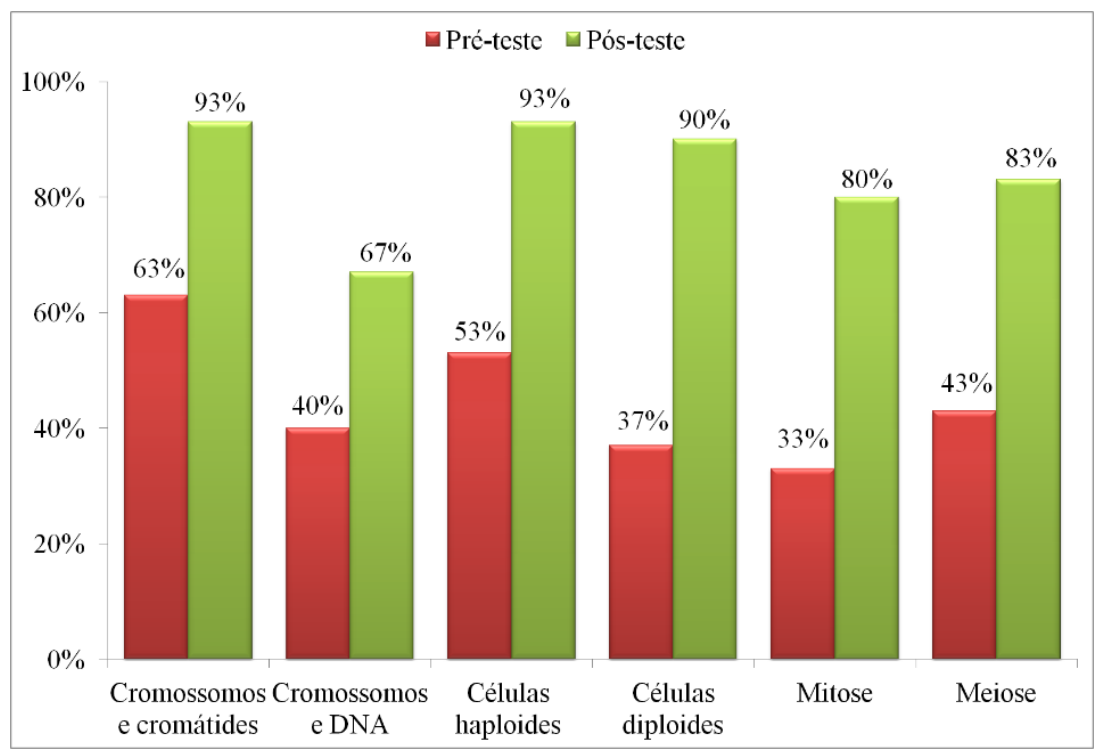

Fonte: Os autores, 2018.

Identificou-se que os modelos didáticos contribuíram em todas as questões e, principalmente, nas relacionadas aos cromossomos e cromátides (93\%), células haploides (93\%) e diploides (90\%). Esses altos índices de acertos podem ter ocorrido devido aos modelos didáticos promoverem uma visão macroscópica das mudanças estruturais dos cromossomos e cromátides durante as etapas da meiose 
e mitose, facilitando também a identificação de células haploides e diploides durante as divisões celulares.

Por conta disso, modelos didáticos são ferramentas eficazes para auxiliar os estudantes a visualizar processos que ocorrem a nível celular, o que permite explicações em aspectos tridimensionais para as estruturas estudadas (ORLANDO et al., 2009; BARROS; OLIVEIRA, 2016). Outro ponto destacável é que, torna os conteúdos científicos palpáveis para os alunos (ASTOLFI; DEVELAY, 2012).

Quanto à questão que estabelece as relações entre cromossomos e DNA, os alunos demonstram uma evolução na capacidade de reconhecer e compreender que são estruturas diferentes, mas relacionadas entre si. Em relação a isso, Cirne (2013) afirma que os alunos possuem uma capacidade de entender sobre os conhecimentos da estrutura do DNA e cromossomos, no entanto, às vezes, há uma apropriação dos termos e não dos conceitos relacionados, como também apontaram os dados do pré-teste.

Apesar disso, de modo geral, foi notado no pós-teste que os alunos souberam indicar que a estrutura do DNA é a principal molécula que forma os cromossomos e que ambos estão localizados no núcleo das células. A evolução desses conhecimentos são indicadores que os estudantes passaram por um processo de mudança conceitual, um conflito cognitivo confere a promoção de uma aprendizagem significativa (MOREIRA, 2012).

O percentual de acertos sobre as questões que investigam as definições e caracterizações da mitose ( $80 \%$ ) e meiose $(83 \%)$ no pós-teste evidenciam que os modelos didáticos propostos foram funcionais quanto aos seus objetivos. Esses dados mostram que antes da aplicação dos modelos didáticos somente $33 \%$ e $43 \%$ dos estudantes possuíam uma capacidade de raciocinar sobre os processos de divisão celular da mitose e meiose, respectivamente.

O uso da modelização provocou melhorias na aprendizagem dos alunos, uma vez também foi observada uma assimilação em reconhecer as sucessivas divisões celulares que levam a formação de células somáticas e gametas, respectivamente, por mitose e meiose. Ou seja, com o uso dos modelos didáticos os estudantes perceberam e ficaram atentos em compreender os processos e não somente os resultados das divisões celulares.

As imagens das mudanças estruturais dos cromossomos durante a mitose e meiose representados nos modelos didáticos puderam atribuir aos alunos uma capacidade de interpretar o fenômeno biológico, tornando o estudante capaz de aplicar o conhecimento obtido em novas problemáticas (TATSCH; SEPEL, 2017). Segundo essas mesmas autoras, a associação das imagens nos modelos didáticos com os conteúdos conceituais faz uma aproximação do mundo microscópio com os alunos, possibilitando os estudantes reconhecerem nas imagens os conceitos e fenômenos descritos no livro didático.

A partir da utilização dos modelos didáticos, foi possível constatar uma evolução na capacidade de compreender as divisões celulares por parte dos estudantes. Os conhecimentos estabelecidos nas aulas expositivas foram elaborados e reformulados pelos alunos, se tornando diferenciados e com capacidade dos mesmos em entender as sucessivas divisões celulares que originam as células somáticas e gametas. Assim, os modelos didáticos foram ferramentas capazes de promover aos alunos maiores assimilações com os modelos científicos da mitose e meiose. Pode-se dizer que os 
modelos didáticos propostos vislumbram a formação de modelos mentais nos alunos (KRAPAS et al., 1997; PAZ et al., 2006).

\section{CONSIDERAÇÕES FINAIS}

Os modelos didáticos, de baixo custo e fácil obtenção, produzidos apresentaram-se como ferramentas eficazes para o ensino e aprendizagem de divisão celular a nível fundamental. Com a prática pedagógica pode-se observar o desenvolvimento de habilidades cognitivas no ensino de mitose e meiose. Os estudantes mostraram evoluções em conceituar, identificar e compreender as estruturas e processos sobre as divisões celulares.

Torna-se, possível concluir que após a aplicação dos modelos didáticos se obteve melhores concepções dos conteúdos de divisão celular por parte dos alunos. Assume se, então, que modelização didática aplicada aos conteúdos conceituais de divisão celular permitiram uma melhor apresentação do modelo conceitual da mitose e meiose para os alunos.

O uso dos modelos didáticos forneceu aos estudantes a capacidade de reconhecer as mudanças estruturais que cromossomos sofrem durante as divisões celulares. Também centralizou a aprendizagem nos processos que formam as novas células diploides na mitose e haploides na meiose, evidenciando que os modelos didáticos como potencialmente significativos para o aprendizado dos alunos, apesar de suas limitações por não representarem os microtúbulos ligados aos cromossomos e áster conectado aos centrossomos com centríolos durante as divisões celulares.

A compreensão dos conhecimentos científicos apresentados na modelização dos processos de mitose e meiose se torna essencial para os alunos progredirem com uma melhor aprendizagem ao longo dos estudos que cercam a divisão celular e construção de novos significados, sobretudo no ensino médio.

\section{REFERÊNCIAS}

ALMEIDA, Iara Gilmony Farias. Utilização de modelo didático no processo de ensinoaprendizagem de divisão celular em uma escola pública de Campina Grande-PB. Campina Grande/PB: UEPB, 2017. Monografia. Universidade Estadual da Paraíba, 2017.

ASTOLFI, Jean-Pierre; DEVELAY, Michel. A didática das ciências. Magda Sento Sé Fonseca [tradução]. 16 ed. Campinas/SP: Papirus, 2012.

BARDIN, Laurence. Análise de conteúdo. São Paulo: Edições 70, 2011.

BARROS, Juliana Sobral de; OLIVEIRA, Vera Lúcia Bahl de. Modelização: um caminho facilitador no ensino de genética. Revista da SBEnBIO. n. 09, p. 6255-6265, 2016.

BRAGA, Cleonice Miguez Dias da Silva. 0 uso de modelos didáticos no ensino de divisão celular na perspectiva da aprendizagem significativa. Brasília. Dissertação: UnB, 2010. Universidade de Brasília, 2010.

CIRNE, Adriana Damasceno Pereira Pinto. Dificuldades de aprendizagem sobre conceitos de genética no ensino fundamental. Natal: Dissertação: UFRN, 2013. Universidade Federal do Rio Grande do Norte, 2013. 
DAVIS, Claúdia; OLIVEIRA, Zilma de Morais Ramos de. Psicologia na educação. 3. ed. São Paulo: Cortez, 2010.

DUSSO, Leamdro; et al. Modelização: uma possibilidade didática no ensino de Biologia. Revista Ensaio, Belo Horizonte, v.15, n. 2, maio/ago., p. 29-44, 2013.

GIL, Antônio Carlos. Como elaborar projetos de pesquisa. 5. ed. São Paulo: Altas, 2010.

KRAPAS, Sonia; et al. Modelos: uma análise de sentidos na literatura de pesquisa em ensino de ciências. Investigações em Ensino de Ciências. v. 2, n. 3, p. 185-205, 1997.

LEDERMAN, Letícia; D'OLIVAL, Francisca Carvalho. Tempo de ciências 8. 2. ed, São Paulo: Editora do Brasil, 2015.

LÜDKE Menga; ANDRÉ, Marli Eliza Dalmazo Afonso de. Pesquisa em educação: abordagens qualitativas. 2. ed. São Paulo: EPU, 2013.

MOREIRA, Marco Antonio. O que é afinal aprendizagem significativa? Qurriculum, La Laguna, Espanha, 2012.

MOUL, Renato Araújo Torres de Melo; SILVA, Flávia Carolina Lins da. A modelização em genética e biologia molecular: ensino de mitose com massa de modelar. Experiências em Ensino de Ciências, v. 12 , n. 2 , p. $118-128,2017$.

ORLANDO, Tereza Cristina; et al. Planejamento, montagem e aplicação de modelos didáticos para uma abordagem de biologia celular e molecular no ensino médio por graduandos de ciências biológicas. Revista Brasileira de Ensino de Bioquímica e Biologia Molecular, n. 1, 2009.

PAZ, Alfredo Müllen da; et al. Modelos e modelizações no ensino de ciências: um estudo da cadeia alimentar. Ensaio, v. 8, n. 2, p. 133-146, 2006.

PEREIRA, Maurivan Barros; MIRANDA, Anderson Fernandes de. O ensino de mitose para a geração Z: uma análise entre dois métodos. Revista Prática Docente (RPD), v. 2, n. 2, p. 255-269, jul./dez., 2017.

SETÚVAL, Francisco Antonio Rodrigues; BEJARANO, Nelson Rui Ribas. Os modelos didáticos com conteúdos de genética e sua importância na formação inicial de professores para o ensino de ciência e biologia. In: ENCONTRO NACIONAL DE PESQUISA EM ENSINO DE CIÊNCIAS, 7. 2009. Anais...Florianópolis: ABECS, 2009.

TATSCH, Helene Mochetti; SEPEL, Lenira Maria Nunes. Baralho mitótico. Genética na escola, v. 12, n. 2, p. 160-175, 2017.

Submissão: 02/07/2018

Aceito: 27/08/2018 